\title{
Flavor aversions and deprivation state
}

\author{
SAM REVUSKY, RICHARD W. POHL, and SHANNON COOMBES \\ Memorial University, St. John's, Newfoundland AlB $3 \times 9$, Canada
}

\begin{abstract}
In the first four experiments, it was found that aversions to saccharin solution produced by contingent poisoning were similar regardless of whether the rats had been trained under the test deprivation or under a different deprivation; the two deprivation states used were thirst and satiety. In Experiment 5, rats were poisoned after drinking grape juice while hungry or poisoned after drinking milk while thirsty, but they were not poisoned after grape-thirst or milk-hunger combinations. In abstract terms, poisoning occurred after $\mathrm{AX}$ and $\mathrm{BY}$ stimulus combinations, but did not occur after $\mathrm{AY}$ and $\mathrm{BX}$ combinations. There was some learning under these discrimination conditions.
\end{abstract}

It is now well established that stimulus properties of food and drink have a strong tendency to become associated with important physiological consequences of feeding and hence to control what is consumed (Garcia \& Koelling, 1966). This allows associative learning to modify or even reverse innate preferences and thus to participate in the regulation of food selection. For instance, the occurrence of toxicosis hours after consumption of a very palatable solution can produce a strong aversion to its flavor. Revusky and Garcia (1970) wondered if learning might have a similar role in the regulation of the amount consumed and the spacing of meals. The learning mechanism they postulated was that internal states, such as hunger and thirst, can become associated with the delayed consequences of feeding, just as flavors can become associated with the delayed consequences of feeding. This theory was based on the now acceptable supposition that selective association of cues with aftereffects is not limited to the association of food and drink with sickness; other classes of stimuli also tend to become selectively associated with classes of aftereffects to which they are causally related in natural environments. For instance, sounds are likely to be selectively associated with dangerous environmental aftereffects (Foree \& LoLordo, 1973) and motor responses are likely to become selectively associated with aftereffects similar to those they are likely to produce in nature (Seligman, 1970; Shettleworth, 1978; Thorndike, 1911). Since internal states are causally related to the consequences of ingestion and are not causally related to, say, the location of rewards in the external environment, it seemed likely to Revusky and Garcia (1970) that the natural role of internal stimulus states would be to permit behavioral control of the internal environment. Sup-

Supported by the National Research Council of Canada. Conversations with David Booth and Eric Holman influenced the content of this paper. We thank Bow Tong Lett and Gerard Martin for reading and criticizing earlier versions of some of this material. porting this suggestion was a well-documented generalization by Bolles (1967, pp. 254-264) that discriminations based on deprivation level are much more easily learned when the reinforcement is food or drink than when it is shock escape. From this and from well-established principles of animal learning, Revusky and Garcia (1970, pp. 66-74) inferred that the occurrence of drive discriminations might be a by-product of the capacity of drive states to control ingestion. This analysis suggests that associations of internal stimuli with the consequences of ingestion might be learned as readily as associations of tastes with the consequences of ingestion. If so, learning based on the use of internal states as cues might have an important role in homeostatic regulation.

\section{EXPERIMENTS 1-4}

A finding by Peck and Ader (1974) seemed to show that internal stimulus states are easily capable of taking on the important role in the learned regulation of food intake postulated by Revusky and Garcia (1970). Peck and Ader reported that significant learned aversions to saccharin solution were obtained only if training and testing occurred under the same deprivation conditions. One deprivation condition used was thirst and the other was satiety. Experiments 1-4 were each independent attempts to confirm the findings of Peck and Ader. All of the experiments included at least eight groups of rats in a three-factor between-groups design. Factor $\mathrm{A}$ was whether or not the rats were poisoned during training. Factor $B$ was whether the rats were thirsty or satiated during the test. Factor $\mathrm{C}$ was whether the deprivation states were the same during training and testing or whether they were different. In the first two experiments, two different doses of lithium chloride toxin were used, so Factor A had three levels. In Experiment 3, one dose of cyclophosphamide toxin was used in a nearly exact replication of the experiment by Peck and Ader (1974). Experiment 4 was a replication of 
Experiment 3, except that rats were subjected to two poisonings during training instead of a single poisoning as in Experiments 1-3.

\section{Method}

Experiment 1. The 98 male Sprague-Dawley rats ranged in adlib weight from 195 to $222 \mathrm{~g}$. They were divided into 12 groups of 8 or 9 rats each with free access to dry Purina chow throughout. All procedures were carried out in the stainless steel home cages, except when the rats were removed briefly during the training procedures for administration of saccharin solution on the tongue or for injections.

Training occurred for six groups after $24 \mathrm{~h}$ of water deprivation; the other six groups were not deprived during training. In each case, about 5 drops of $.6 \%(\mathrm{w} / \mathrm{v})$ of sodium saccharin solution were placed on the tongue of each rat in the way described by Peck and Ader (1974). Just after this, two of the groups that were subjected to each training deprivation $(0 \mathrm{~h}$ or $24 \mathrm{~h})$ were injected intraperitoneally with $15 \mathrm{mg}$ of $\mathrm{LiCl}$ in $.75 \mathrm{ml}$ of a $2.0 \% \mathrm{w} / \mathrm{v}$ solution, two groups were injected with $30 \mathrm{mg}$ of $\mathrm{LiCl}$ in a $2 \%$ solution, and two groups were injected with $1.5 \mathrm{ml}$ of normal saline. Because of the narrow range of body weights, doses were absolute instead of adjusted to body weight. One hour later, the rats that had been deprived were given free access to water.

There were three tests in the course of 3 successive days, beginning 2 days after training. Each test consisted of $3 \mathrm{~h}$ of free access to $.6 \%$ saccharin solution; during the test, this was the only source of fluid. Of each two groups subjected to identical training procedures, one group was tested while satiated and the other while thirsty. Those tested while satiated had free access to unflavored water after training, except during the tests. For those tested while thirsty, the water bottle was removed $24 \mathrm{~h}$ after training and their only source of water was during the tests; thus, the first test was conducted after $22.5 \mathrm{~h}$ of deprivation and the remaining tests were conducted after 21 h of deprivation.

Experiment 2. The 96 male rats, with ad-lib weights of 199 . $228 \mathrm{~g}$, were divided into 12 groups of 8 rats each. Training was conducted exactly as in Experiment 1, except that the saccharin solution was $.1 \%$, the doses of $\mathrm{LiCl}$ in $2 \%$ solution were 20 and $40 \mathrm{mg}$, and the dose of normal saline was $2.0 \mathrm{ml}$. Testing began under the same deprivation conditions as in Experiment 1, but there was only one 23 -h test of free access to unflavored water and saccharin solution. The saccharin solution was always on the right, which was where unflavored water had been presented earlier. The bottles were weighed before the test, after $2.5 \mathrm{~h}$, after another $2.5 \mathrm{~h}$, and at the end of the test. The results obtained from each weighing were treated as successive choice tests.

Experiment 3. This was an exact replication of the procedure reported by Peck and Ader (1974), except in the minor differences indicated and, of course, in unavoidable differences in laboratory conditions and equipment. One difference was that while Peck and Ader kept their rats on a 12-h light-dark cycle, our rats were maintained on continuous light. Another, more minor, difference was that while Peck and Ader's rats were maintained at $72^{\circ} \pm 2.0^{\circ} \mathrm{F}$, our average temperature was about $73.5^{\circ} \pm 1.5^{\circ} \mathrm{F}$. Also, while Peck and Ader used both male and female rats, 90-120 days old, we used only males estimated, on the basis of their ad-lib weights, to be about 7 weeks old.

Our 100 male Sprague-Dawley rats, $192-221 \mathrm{~g}$ ad-lib weight, were divided into 8 groups of 12 or 13 each. Subject to the qualifications in the preceding paragraph, the procedure of Peck and Ader was replicated exactly. The training procedure was similar to that of Experiment 2, except that the toxin was $1 \mathrm{ml} / \mathrm{kg}$ of a $50-\mathrm{mg} / \mathrm{ml}$ solution of cyclophosphamide in a vehicle of $25 \%$ ethanol; the rats not subjected to the toxin were subjected to an equal volume of the vehicle. Testing was conducted exactly as in Experiment 2, except that all rats received ad-lib water for 2 days after training instead of 1 day as in Experiment 2.
Experiment 4. The taste aversions obtained in Experiment 3 turned out to be weaker than those obtained by Peck and Ader (1974) and, hence, there was a possibility that it was not a fair replication of their experiment. Therefore, we repeated the procedure of Experiment 3, except that we used two poisonings instead of one. We outline the procedure once again to prevent confusion. The 96 male Sprague-Dawley rats, 191-218 g ad-lib weight, were divided into 8 groups of 12 each. On Day 1 , the rats were exposed to 5 drops of $.1 \%$ saccharin solution either while $\mathbf{2 4} \mathrm{h}$ thirsty or while satiated for water, and then were subjected to either the placebo or the $50-\mathrm{mg} / \mathrm{kg}$ cyclophosphamide injection. One hour later, all rats were given free access to unflavored water until Day 3 . Then the rats assigned to thirst during training were deprived of water, while the rats assigned to satiety were not deprived. Another training trial was administered on Day 4 , followed, after $1 \mathrm{~h}$, by free access to unflavored water until Day 6 for the rats scheduled for testing while thirsty and until Day 7 for the remainder. The test on Day 7 was $23 \mathrm{~h}$ of free access to both $.1 \%$ saccharin solution and unflavored water, with bottle weighings after $2.5 \mathrm{~h}$, after another $2.5 \mathrm{~h}$, and at the end of the session.

\section{Results and Discussion}

For Experiment 1, the test datum was the amount in grams of saccharin solution consumed. For Experiments $2-4$, it was preference for saccharin defined as saccharin solution consumed during the test divided by total fluid consumption (saccharin solution plus unflavored water). Like Peck and Ader (1974), we analyzed the results of each test in each experiment separately by means of a three-dimensional ANOVA; we omitted the rats subjected to the lower dose of lithium in Experiments 1 and 2, thus including only the rats subjected to the higher dose and to the placebo, since this method does not change our conclusions and makes our analyses similar to those of Peck and Ader. Factor A of the ANOVA was whether the rat was subjected to poison or placebo during training, Factor $\mathbf{B}$ was whether the test was conducted while the rat was satiated or thirsty, and Factor $\mathrm{C}$ was whether the thirst levels during testing and training were the same or different. Table 1 shows the Fs obtained by this method for Tests 1 and 2 of each experiment; each $F$ has 1 treatment degree of freedom, while the error degrees of freedom are 58 for Experiment 1, 56 for Experiment 2, 92 for Experiment 3, and 88 for Experiment 4. In Test 3, the only significant results were for the $B$ factor in Experiment $1(\mathrm{~F}=25.4, \mathrm{p}<.001)$ and the $\mathrm{A}$ factor in Experiment $3(F=12.7, p<.001)$. It is evident that during the first two tests of each experiment, the $A$ and $B$ factors yielded significant results. The significant results obtained from Factor $A$ are evidence that taste aversion learning occurred. The significant effect of Factor B means that the scores were affected by whether the rats were thirsty or satiated at the beginning of testing. In Experiment 1, when a one-bottle test of saccharin preference was used, consumption was higher while the rats were thirsty. In Experiments 2, 3, and 4, the proportions of saccharin consumed were higher when the rats 
Table 1

Results of Separate ANOVAs on Tests 1 and 2 of Each Experiment

\begin{tabular}{|c|c|c|c|c|c|c|c|c|}
\hline & \multicolumn{2}{|c|}{ Experiment 1} & \multicolumn{2}{|c|}{ Experiment 2} & \multicolumn{2}{|c|}{ Experiment 3} & \multicolumn{2}{|c|}{ Experiment 4} \\
\hline & Test 1 & Test 2 & Test 1 & Test 2 & Test 1 & Test 2 & Test 1 & Test 2 \\
\hline $\mathrm{F}(\mathrm{A})$ & $5.83^{*}$ & $6.62^{*}$ & $10.30^{* *}$ & $9.82 * *$ & $6.81^{*}$ & $9.63^{* *}$ & $43.00 \dagger$ & $17.60 \div$ \\
\hline$F(B)$ & $91.10 \dagger$ & $96.00 \dagger$ & $27.00 \dagger$ & $15.80 \dagger$ & $50.10^{\dagger}$ & $14.10^{\circ}$ & $58.00 \dagger$ & $4.82^{*}$ \\
\hline$F(C)$ & .00 & .32 & .88 & .06 & 2.04 & .33 & $6.11^{*}$ & 2.42 \\
\hline$F(A B)$ & 2.10 & .21 & .02 & 2.45 & .37 & .86 & .88 & .01 \\
\hline$F(A C)$ & .03 & .02 & .00 & .03 & 1.80 & .03 & 1.18 & 3.16 \\
\hline $\mathrm{F}(\mathrm{BC})$ & .68 & .07 & .00 & 1.27 & .02 & .12 & 3.59 & 2.21 \\
\hline$F(A B C)$ & .00 & 1.59 & .98 & .18 & .91 & .51 & $9.92 * *$ & .85 \\
\hline
\end{tabular}

${ }^{*} p<.05 . \quad *{ }^{*} p<.01 . \quad t_{p}<.001$.

were satiated for water. All of these effects are typical of taste aversion experiments.

Factor $\mathrm{C}$ was whether the deprivation state during testing was the same as or different from that during training. If Peck and Ader's (1974) results had been replicated, there would have been a significant $\mathrm{A}$ by $\mathrm{C}$ interaction, such that the difference between the scores of rats subjected to the toxin and those subjected to the placebo would be greater if the test deprivation condition were the same as the training deprivation. None of the ANOVAs shown in Table 1 yielded a significant $\mathrm{A}$ by $\mathrm{C}$ interaction. Sometimes interactions in ANOVAs can be masked when each of the interacting factors has main effects or when there are higher order interactions ( $\mathrm{A}$ by $\mathrm{B}$ by $\mathrm{C}$ in this case), but this was not so for the present $A$ by $C$ interactions. Table 1 does show an apparently significant $C$ effect and an apparently significant $A$ by $\mathrm{B}$ by $\mathrm{C}$ interaction during the first test of Experiment 4 , but, as will be seen in Table 5 , neither of these results confirm those of Peck and Ader.

We will present data for only the first test in each experiment, since, in our judgment (based on inspection of the results), presentation of the remainder of the data would not add any useful information. In Experiments 2, 3, and 4, all tests after the first test were conducted under satiated conditions, since the rats had had at least $2.5 \mathrm{~h}$ of free access to both saccharin solution and unflavored water. In the absence of state dependence during the first test, it is hard to see how results from subsequent tests would be relevant to the issue of whether taste aversions are state dependent. Table 2 shows the results for the first test of Experiment 1 in terms of actual amounts consumed, while Tables 3,4 , and 5 show the results of Experiments 2, 3, and 4, respectively, in terms of percentages consumed of saccharin solution relative to total consumption.

Tables 2-5 do not show state dependence, which would be exhibited as a difference between a poisoned group and its placebo control that was greater when training and test drives were the same than when they were different. We compared these differences directly to insure that the lack of significant $\mathrm{A}$ by $\mathrm{C}$ interactions in Table 1 was not somehow due to insensi-
Table 2

\begin{tabular}{|c|c|c|c|}
\hline \multirow{2}{*}{$\begin{array}{c}\text { Test } \\
\text { Drive }\end{array}$} & \multirow[b]{2}{*}{ Dose } & \multicolumn{2}{|c|}{ Training vs. Test Drive } \\
\hline & & Same & Different \\
\hline satiated & placebo & 9.68 & 8.34 \\
\hline satiated & $15 \mathrm{mg} \mathrm{LiCl}$ & 4.38 & 4.69 \\
\hline satiated & $30 \mathrm{mg} \mathrm{LiCl}$ & 4.35 & 3.52 \\
\hline thirsty & placebo & 19.20 & 20.10 \\
\hline thirsty & $15 \mathrm{mg} \mathrm{LiCl}$ & 17.51 & 17.78 \\
\hline thirsty & $30 \mathrm{mg} \mathrm{LiCl}$ & 17.74 & 19.02 \\
\hline
\end{tabular}

Table 3

Mean Percentage of Saccharin Solution Consumed by Each Group in Experiment 2 During the First Test

\begin{tabular}{cccc} 
Test & & \multicolumn{2}{c}{ Training vs. Test Drive } \\
\cline { 3 - 4 } Drive & Dose & Same & Different \\
\hline satiated & placebo & 85.5 & 85.9 \\
satiated & $20 \mathrm{mg} \mathrm{LiCl}$ & 87.2 & 84.6 \\
satiated & $40 \mathrm{mg} \mathrm{LiCl}$ & 69.2 & 56.7 \\
thirsty & placebo & 56.4 & 42.4 \\
thirsty & $20 \mathrm{mg} \mathrm{LiCl}$ & 37.9 & 45.6 \\
thirsty & $40 \mathrm{mg} \mathrm{LiCl}$ & 28.4 & 28.6 \\
\hline
\end{tabular}

Table 4

Mean Percentage of Saccharin Solution Consumed by Each Group in Experiment 3 During the First Test

\begin{tabular}{|c|c|c|c|}
\hline \multirow{2}{*}{$\begin{array}{c}\text { Test } \\
\text { Drive }\end{array}$} & \multirow[b]{2}{*}{ Dose } & \multicolumn{2}{|c|}{ Training vs. Test Drive } \\
\hline & & Same & Different \\
\hline $\begin{array}{l}\text { satiated } \\
\text { satiated }\end{array}$ & $\begin{array}{l}\text { placebo } \\
\text { drug }\end{array}$ & $\begin{array}{l}70.3 \\
61.7\end{array}$ & $\begin{array}{l}63.3 \\
57.5\end{array}$ \\
\hline $\begin{array}{l}\text { thirsty } \\
\text { thirsty }\end{array}$ & $\begin{array}{l}\text { placebo } \\
\text { drug }\end{array}$ & $\begin{array}{l}50.2 \\
30.2\end{array}$ & $\begin{array}{l}37.1 \\
33.8\end{array}$ \\
\hline
\end{tabular}

Table 5

Mean Percentage of Saccharin Solution Consumed by Each Group in Experiment 4 During the First Test

\begin{tabular}{clcc}
\hline & & \multicolumn{2}{c}{ Training vs. Test Drive } \\
\cline { 3 - 4 } Test & Dose & Same & Different \\
\hline satiated & placebo & 84.2 & 83.7 \\
satiated & drug & 72.1 & 40.4 \\
thirsty & placebo & 57.3 & 47.5 \\
thirsty & drug & 28.8 & 34.4 \\
\hline
\end{tabular}


tivity of the ANOVAs. In Experiment 1 (Table 2), the mean difference between poisoned and control groups was $3.4 \mathrm{~g}$ when the training and test drives were the same vs. $3.0 \mathrm{~g}$ when the training and test drives were different. In Experiment 2 (Table 3), the differences in percentage of saccharin consumption were $15.3 \%$ and $10.3 \%$, respectively, for the "same" and "different" conditions. The largest difference in favor of the "same" condition was in Experiment 3 (Table 4), $14.3 \%$ (same) vs. $4.6 \%$ (different). However, the relative magnitudes of these differences were reversed in Experiment 4 (Table 5), 20.3\% (same) vs. $28.2 \%$ (different). In this last case, the difference between poisoned and placebo groups was larger in the "same" condition than in the "different" condition when the animals were tested when thirsty, but the opposite was true when the animals were tested when satiated; this is the source of the $A B C$ interaction for the result, which is shown in Table 1. In view of the very large number of statistical evaluations that were made in the four experiments, and the fact that no similar interaction was found in the other three experiments, we believe this to be a chance result.

The pattern of results in these four experiments indicates that conditioned taste aversions generalize almost completely between thirst and satiety, or, in different terms, flavor aversions do not seem to be generally state dependent. Another failure to find state dependence in taste aversions has been reported by Gillette, Bellingham, and Martin (1979).

\section{EXPERIMENT 5}

The Peck-Ader procedure was a generalization decrement or state dependency procedure, which differed from a discrimination learning procedure, in which training occurs both under reinforced and nonreinforced conditions. Experiment 5 was an attempt to involve deprivation states in the control of feeding by means of a discrimination learning procedure. The rats in Group GH became sick if they drank grape juice while hungry, but did not become sick if they drank the same grape juice while thirsty; the same rats became sick if they drank milk while thirsty, but did not become sick if they drank milk while hungry. The rats in Group GT were subjected to the counterbalanced procedure. The sequences of four-trial cycles to which each group was subjected are outlined in Table 6: First, the drive state is in- dicated, then the substance consumed, and, finally, an injection of lithium if it was administered.

The conditional flavor-drive discrimination outlined in Table 6 is a very difficult task, but such tasks have traditionally been considered necessary in experiments designed to investigate how drive stimuli can function as discriminative cues. Recently, Capaldi and Davidson (1979) devised a simpler drive discrimination task for rats in a runway and showed much faster learning involving drive stimuli than had hitherto been obtained; when they tried a conditional discrimination roughly like that in Table 6 , the learning was as slow as usual. Unfortunately, we were not able to think of a way to use a simpler procedure to demonstrate the possible role of drive stimuli in the selection of food. However, despite the difficulty of the present procedure, it seemed very likely that it would result in learning, since rats learn similar compound discriminations involving two flavors (Luongo, 1976) or a flavor and an odor (Taukulis \& Revusky, 1975).

The experimental procedure was long and complex in an attempt to avoid a large number of potential technical problems. In training a compound discrimination based on a toxicosis US, it is best to start with low doses of the toxic agent so that the animal will not initially develop such a strong aversion to the flavors that it will no longer sample them and hence have no chance to learn the compound discrimination (Luongo, 1976; Taukulis \& Revusky, 1975). For the same reason, one cannot have a random sequence of the four types of trials indicated for each group in Table 6; after many successive toxicosis trials for a particular flavored solution (which might well occur by chance), the rat might stop consuming that solution entirely. Thus, the fixed sequences shown in Table 6 were deemed desirable.

\begin{abstract}
Method
Subjects. The 24 male Sprague-Dawley rats weighed $160-180 \mathrm{~g}$ ad lib just prior to the experiment and were divided into two groups of 12 each. All procedures, except for weighings and injections, occurred in stainless steel home cages, which contained a hopper of dry Purina chow and a water bottle. Each Friday, the water was removed for $72 \mathrm{~h}$; each Tuesday, the food was removed for $48 \mathrm{~h}$. The weight ranges of the rats after 5,12 , and 23 weeks were, respectively, 186-240, 199-261, and 222-318 g.

Materials. The grape juice and milk solutions were equated roughly for both caloric and water value. The grape juice was $50 \%$ by volume of Welch unsweetened grape juice and $50 \%$ of $10 \%(w / v)$ sucrose solution. The milk was a solution of $40 \%$ by volume of Carnation brand evaporated milk.
\end{abstract}

Table 6

Sequence of Trials in Each 2-Week Training Cycle of Experiment 5 for Groups GH and GT

\begin{tabular}{cllll}
\hline Group & Trial 1 & Trial 2 & \multicolumn{1}{c}{ Trial 3 } & Trial 4 \\
\hline GH & Thirst $\rightarrow$ Grape & Hunger $\rightarrow$ Milk & Thirst $\rightarrow$ Milk $\rightarrow$ Li & Hunger $\rightarrow$ Grape $\rightarrow$ Li \\
GT & Thirst $\rightarrow$ Milk & Hunger $\rightarrow$ Grape & Thirst $\rightarrow$ Grape $\rightarrow$ Li & Hunger $\rightarrow$ Milk $\rightarrow$ Li \\
\hline
\end{tabular}

Note-Li refers to lithium toxicosis. 
Training procedure. There were two trials per week, during which the rats had 30 -min access to grape or milk solutions. The first trial was on Monday while the rats were 64-65 h thirsty; the second was on Thursday while they were $40-41 \mathrm{~h}$ hungry. Because any given duration of food deprivation is more debilitating than an equal duration of water deprivation (Bolles, 1967), the hunger and thirst levels were more similar than if they had each been based on the same length of deprivation. The sequence of four trials in each training cycle of 2 weeks is indicated in Table 6 for each group. If the rat was not scheduled to be subjected to toxicosis and had consumed less than $10 \mathrm{~g}$ of the grape or milk solutions, it was immediately given an extra ration in a steel cup so that its total consumption would be $10 \mathrm{~g}$. If a rat was scheduled for toxicosis, it was injected, as the bottle of grape or milk solution was removed, with $2.0 \%(\mathrm{w} / \mathrm{v})$ lithium chloride solution, ip, with a $25-27$ ga needle. The dose was $.25 \mathrm{ml}$ in Cycle $1, .50 \mathrm{ml}$ in Cycle 2, .75 ml in Cycles $3-6$, and $1.0 \mathrm{ml}$ in Cycles 7 and 8 . Even the highest, $1.0 \mathrm{ml}$, dose is only about half the dose usually used in flavor aversion experiments (Nachman \& Ashe, 1973).

Testing procedure. Testing started at the end of Cycle 8 of training. Three rats in each group began the testing procedure at the end of Cycle 8, while other subgroups of three rats each began after one, two, or three trials of Cycle 9. This was done to average out the shifts in preference bound to occur in the course of the different types of training trials. Six choice trials between the grape and milk solutions were substituted for the training trials in the course of 3 weeks. The 30 -min duration of trials and the drive maintenance regimen remained as before so that the six tests would be administered in three pairs under alternate hunger and thirst.

Additional training and testing. After the six choice tests had been completed, the rats were returned to Cycle 9 of training in order to complete it. For instance, if a rat had completed two trials of Cycle 9 prior to testing, its next trial was the third trial, as shown in Table 6. Then Training Cycles 10 and 11 were administered with a $2.0 \mathrm{ml}$ dose of $2.0 \% \mathrm{LiCl}$ on poisoned trials. This was followed by another five pairs of alternating hunger and thirst tests, with different animals starting at the point of the 12th training cycle corresponding to the point in the 9th training cycle at which they had been tested earlier.

\section{Results}

The choice tests showed that both groups learned the compound flavor-drive discrimination. As shown on the left side of Figure 1, Group GH had a lower

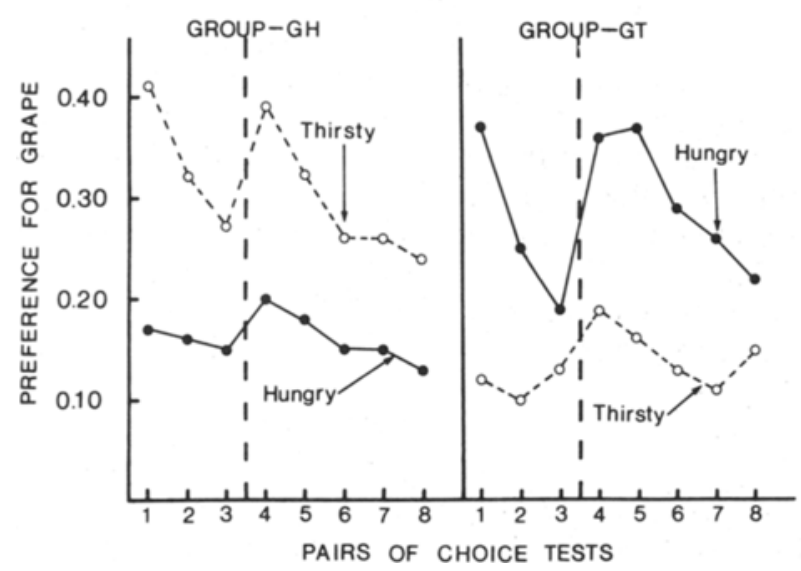

Figure 1. Grape juice consumption divided by total consumed for rats given a choice between grape juice and milk. Each group exhibited a lower preference for grape juice in the drive state in which grape juice was paired with toxicosis. preference for grape juice relative to milk when it was hungry than when it was thirsty; this reflects the fact that it was made sick after drinking grape juice while hungry and after drinking milk while thirsty. The first three pairs of tests were administered after eight cycles of training and the last five pairs were administered after 11 cycles. Preference for grape juice was calculated as amount of grape juice consumed (in grams) divided by total amount (both grape juice and milk) consumed. This measure equals .50 when equal amounts of milk and grape juice are consumed, is smaller than .50 when milk is preferred to grape juice, and is larger than .50 when grape juice is preferred to milk. Given that the choice was between grape juice and milk, it was arbitrary whether the preference was to be expressed in terms of a preference for grape juice or for milk. By a paired $t$ test, the differences for Group GH between the hunger and thirst condition were significant over the combined first three pairs of tests $[t(11)=5.39$, $\mathrm{p}<.001]$ and over the combined last five pairs [t(11) $=3.17, \mathrm{p}<.01]$. The right side of Figure 1 shows that Group GT also learned the discrimination. Its preference for grape juice relative to milk was lower when thirsty than when hungry $[\mathrm{t}(11)=2.42, \mathrm{p}<.05$, for the first three pairs of data points; $t(11)=3.13$, $\mathrm{p}<.01$, for the last five pairs of data points].

\section{Discussion}

By the standards of compound discriminationlearning experiments in which the cues are external, and the learning is demonstrated by means of a motor response, the learning shown was very good. After only eight cycles of training, the preference for grape juice was half as high during the punished as during the unpunished condition, even though a low dose of the toxin was used for technical reasons. Although exact comparisons are impossible, there was no clear evidence that learning was inferior to that obtained by Luongo (1976) in taste-tastecompound discriminations or by Taukulis and Revusky (1975) in taste-odor-compound discriminations if allowance is made for the relatively few acquisition trials in the present experiment.

However, from our vantage point, based on a concern with the possible validity of the Revusky-Garcia (1970) drive theory, the discrimination learning seemed poor. By extrapolation from the work of Revusky and Bedarf (1967), which also involved a choice between grape juice and milk, there can be little doubt that rats can easily learn to avoid milk nearly entirely in favor of grape juice after a single trial under conditions that are not optimal. Had such perfect discrimination learning been exhibited, the $\mathrm{GH}$ rats would have avoided milk almost entirely in favor of grape juice while thirsty and hence exhibited preferences near 1.0 in the left graph of Figure 1, for they had been made sick after drinking milk while 
thirsty but had not been made sick after drinking grape juice while thirsty. In reality, however, the mean preferences were always below .50, indicating that the discrimination procedure was not the main determinant of relative preference; the rats preferred milk to grape juice even under the drive state in which drinking milk had been paired with toxicosis and drinking grape juice had been safe. Our tentative impression is that the control of ingestion by hunger and thirst states shown in Figure 1 is too weak to take on the theoretical burden demanded by the RevuskyGarcia theory. Had such control been as strong as that reported by Peck and Ader (1974), we would feel very confident of the theory's merits. Another reason not to regard the present results as support for the Revusky-Garcia theory is that the discrimination shown in Figure 1 was obtained in such an extremely unnatural way that it is unlikely that the process isolated would be of any practical biological importance. Although it required only eight learning cycles to reach the level shown in Figure 1, it should be remembered that each cycle required 2 weeks. Furthermore, even the small magnitude of discrimination learning shown in Figure 1 may be exaggerated since, as Steven Maier pointed out to us, there is a possibility that some of the stimulus control occurred because dry chow was present during thirst sessions but not during hunger sessions. However, on the basis of unpublished data involving conditional discriminations with drug states rather than drives, we are quite certain that this is a minor factor.

\section{GENERAL DISCUSSION}

These experiments began as an attempt to find support for the theory of Revusky and Garcia (1970) that learned associations of hunger and thirst states with the homeostatic consequences of ingestion are responsible for some of the regulation of food intake. This carries the implication that hunger and thirst are capable of acting as discriminative stimuli for the delayed consequences of ingestion in much the same way flavors can. Experiments $1-4$ were an investigation of the possibility that Revusky and Garcia had actually been too conservative in their speculations. Peck and Ader (1974) seemed to show that taste aversions were specific to training deprivation states even without any specific discrimination training. However, we were not able to confirm this result in any of four experiments, and so it is clear that their result has little generality.

Experiment 5 showed that, with extensive discrimination training, the rat's selection of what it consumes can be partly controlled by drive stimuli. One group of rats was taught that drinking grape juice while hungry results in sickness and that drinking milk while thirsty results in sickness; it also was taught that the converse hunger-milk and thirst-grape combinations were safe. A second group was taught the counterbalanced discrimination. Although learning occurred, we doubt whether the discrimination was marked enough to support Revusky and Garcia's (1970) theory that learned associations between internal stimulus states and the physiological consequences of feeding help regulate the intake of food and water. However, we still cannot find anything wrong with the reasoning of Revusky and Garcia or with earlier results supportive of their approach (Kurtz \& Jarka, 1968; Revusky, 1967, 1968, 1974), and the present results do not suggest a better approach. It is clear that rats can use drive states as cues by which to locate food or even to find a place safe from shock (Bolles, 1967). Hence, such states can function as discriminative stimuli. Revusky and Garcia supposed that such discriminations were nonfunctional, since the location of food or a place of safety does not depend on the animal's drive state. Holding to the position that no discriminative capacities can be entirely nonfunctional, they guessed that the capacity of drive states to function as discriminative stimuli in traditional learning tasks was an epiphenomenon of their role in the regulation of food intake. Because the consequences of food intake are likely to be delayed, it seemed reasonable to expect drive stimuli to become selectively associated with delayed sickness about as strongly as tastes do.

It is possible that the present results would have confirmed the Revusky-Garcia analysis more strongly had solid foods been used instead of fluids; Gillette, Martin, and Bellingham (Note 1) have shown that, in chickens, the associative properties of solid foods are different from those of liquids. Perhaps something similar is true for rats. Another possibility is that associative learning enters into the regulation of food intake by internal stimulus states in a different manner than that postulated by Revusky and Garcia (1970). For instance, Booth $(1972,1979)$ has postulated a regulatory role for learning that involves satiety cues and is quite different from the RevuskyGarcia approach; his position does not seem to be contradicted by the present results. A related possibility is that deprivation stimuli are selectively associated with nutritional aftereffects and not with a US like lithium sickness. Still other possibilities have been discussed elsewhere (Revusky, Taukulis, \& Coombes, in press).

\section{REFERENCE NOTE}

1. Gillette, K. D., Martin, G. M., \& Bellingham, W. P Asymmetrical use of colour and laste cues in fond and water consumption. Paper read at the Australian Experimental Psychology Conference, Melbourne, 1978.

\section{REFERENCES}

Bolles, R. C. Theory of motivation. New York: Harper \& Row, 1967. 
Boorth, D. A. Conditioned satiety in the rat. Journal of Comparative and Physiological Psychology, 1972, 81, 457-471.

Booth, D. A. Metabolism and the control of feeding in men and animals. In K. Brown \& S. J. Cooper (Eds.), Chemical influences on behavior. New York: Academic Press, 1979.

Capaldi, E. D., \& Davidson, T. L. Control of instrumental behavior by deprivation stimuli. Journal of Experimental Psychology: Animal Behavior Processes, 1979, 5, 355-367.

Foree, D. D., \& LoLordo, V. M. Attention in the pigeon: Differential effects of food-getting versus shock-avoidance procedures. Journal of Comparative and Physiological Psychology, $1973,85,551-558$.

Garcia, J., \& Konthing, R. A. Relation of cue to consequence in avoidance learning. Psychonomic Science, 1966, 4, 123-124.

Gillette, K. D., Bellingham, W. P., \& Martin, G. M. Transfer of a taste aversion from food to water under various states of deprivation. Animal Learning \& Behavior, 1979, 7, 441-446.

KuR'z, K. H., \& JaRKa, R. G. A position preference based on differential food privation. Journal of Comparative and Physiological Psychology, 1968, 66, 518-521.

Luongo. A. F. Stimulus selection in discriminative taste aversion learning in the rat. Animal Learning \& Behavior, 1976, 4, 225-230.

Nachman, M., \& Ashi, J. H. Learned laste aversions in rats as a function of dosage, concentration, and route of administration of LiCl. Physiology \& Behavior, 1973, 10, 73-78.

Peck, J. H., \& ADkr, R. Illness-induced taste aversion under states of deprivation and satiation. Animal Learning \& Behav. ior, 1974, 2, 6-8.
Revusky, S. H. Hunger level during food consumption: Effects on subsequent preference. Psychonomic Science, 1967, 7, $109-110$

Rrvusky, S. H. Effects of thirst level during the consumption of flavored water on subsequent preference. Journal of Comparative and Physiological Psychology, 1968, 66, 777-779.

RFvUsky, S. Retention of a learned increase in the preference for a flavored solution. Behavioral Biology, 1974, 11, 121-125.

Revusky, S. H., \& Bedarf, E. W. Association of illness with the prior consumption of novel foods. Science, 1967, 155, 219-220.

Revusky, S., \& Garcia, J. Learned associations over long delays. In G. H. Bower (Ed.), The psychology of learning and motivation: Advances in theory and research (Vol. 4). New York: Academic Press, 1970.

Revusky, S.. Taukulis, H. K., \& Coombes, S. Dependence of the Avfail effect on the sequence of training operations. Behavioral and Neural Biology, in press.

Sirigman, M. E. P. On the generality of the laws of learning. Psuchological Review, 1970, 77, 406-418.

SHFTtLFORTH, S. J. Reinforcement and organization of behavior in golden hamsters: Punishment of three action patterns. Learning and Motivation, 1978, 9, 99-123.

Taukulis, H. K., \& Rrvusky, S. Odor as a conditioned inhibitor: Applicability of the Rescorla-Wagner model to feeding behavior. Learning and Motivation, 1975, 6, 11-27.

Thonndikf, E. L. Animal intelligence. New York: Hafner, 1911.

(Received for publication November 13, 1979; revision accepted April 8, 1980.) 